\title{
Prevalence of chronic obstructive pulmonary disease in asymptomatic smokers
}

\author{
This article was published in the following Dove Press journal: \\ International Journal of COPD \\ 2 November 2015 \\ Number of times this article has been viewed
}

\section{Raúl H Sansores \\ Mónica Velázquez-Uncal \\ Oliver Pérez-Bautista \\ Jaime Villalba-Caloca \\ Ramcés Falfán-Valencia \\ Alejandra Ramírez-Venegas}

Tobacco Smoking and COPD Research Department, National Institute of Respiratory Diseases, Ismael Cosio Villegas, Mexico City, Mexico
Correspondence: Alejandra RamírezVenegas

Departamento de Investigación en Tabaquismo y EPOC, Instituto Nacional de Enfermedades Respiratorias, Ismael Cosio Villegas, Tlalpan \#4502, I 4080 Mexico City, Mexico Email aleravas@hotmail.com
Background: Physicians do not routinely recommend smokers to undergo spirometry unless they are symptomatic.

Objective: To test the hypothesis that there are a significant number of asymptomatic smokers with chronic obstructive pulmonary disease (COPD), we estimated the prevalence of COPD in a group of asymptomatic smokers.

Methods: Two thousand nine hundred and sixty-one smokers with a cumulative consumption history of at least 10 pack-years, either smokers with symptoms or smokers without symptoms (WOS) were invited to perform a spirometry and complete a symptom questionnaire.

Results: Six hundred and thirty-seven (21.5\%) smokers had no symptoms, whereas 2,324 $(78.5 \%)$ had at least one symptom. The prevalence of COPD in subjects WOS was $1.5 \%$ when considering the whole group of smokers $(45 / 2,961)$ and $7 \%$ when considering only the group WOS (45/637). From 329 smokers with COPD, 13.7\% were WOS. Subjects WOS were younger, had better lung function and lower cumulative consumption of cigarettes, estimated as both cigarettes per day and pack-years. According to severity of airflow limitation, $69 \%$ vs $87 \%$ of subjects were classified as Global Initiative for Chronic Obstructive Lung Disease stages I-II in the WOS and smokers with symptoms groups, respectively $(P<0.001)$. A multivariate analysis showed that forced expiratory volume in 1 second $(\mathrm{mL})$ was the only predictive factor for COPD in asymptomatic smokers.

Conclusion: Prevalence of COPD in asymptomatic smokers is $1.5 \%$. This number of asymptomatic smokers may be excluded from the benefit of an "early" intervention, not just pharmacological but also from smoking cessation counseling. The higher forced expiratory volume in 1 second may contribute to prevent early diagnosis.

Keywords: COPD, asymptomatic smokers, early diagnosis

\section{Introduction}

Chronic obstructive pulmonary disease (COPD), characterized by a poorly reversible limitation in airflow, is predicted to be the third most frequent cause of death worldwide by $2020{ }^{1}$ Therefore, early diagnosis of COPD is relevant both to prevent disease progression as well as to treat it. The diagnosis and risk of death in patients with COPD is usually estimated with the use of the forced expiratory volume in 1 second $\left(\mathrm{FEV}_{1}\right)$. However, physicians do not routinely recommend smokers to undergo spirometry, 2,3 unless they are symptomatic, particularly with dyspnea. An important and unknown number of patients with COPD seek medical help for the first time, either during a physician's office visit or during an emergency room event in the face of an exacerbation. Because it is feasible that the disease initiation was not on the day of the exacerbation, one may assume that those patients were asymptomatic. ${ }^{4}$

The large majority of information on early diagnosis of COPD results from casefinding studies, which is based on the presence of chronic respiratory symptoms. 
Information resulting from screening studies that aim to apply spirometry to all smokers without considering the presence of symptoms is scarce. Zielinski et $\mathrm{al}^{5}$ tested $>100,000$ smokers and found among the prevalent cases $(20.3 \%)$ of COPD that almost $64 \%$ of subjects had respiratory symptoms, mainly cough. Recently, we found in a screening study that, among the $13.3 \%$ of smokers who had COPD, up to $56 \%$ had symptoms. ${ }^{6}$ Both studies suggest the existence of a number of smokers without symptoms (WOS) having COPD whose actual prevalence is unknown. These data are relevant because of the increased COPD subdiagnosis. $^{7}$

Therefore, to test the hypothesis that there are a significant number of asymptomatic smokers with COPD, we estimated the prevalence of COPD in a group of smokers in whom spirometry and a questionnaire on symptoms were carried out.

\section{Methods}

This study included 2,961 smokers from a database of subjects enrolled in a continuing program of early detection of COPD. ${ }^{6}$ The study was performed in the COPD and Smoking Cessation Clinic of the National Institute of Respiratory Diseases (INER) in Mexico City. INER is a public tertiary care center devoted to medical care, teaching and research focusing on respiratory diseases. The original project was approved by the ethics committee of the INER (Comité de Ciencia y Bioética en Investigación, approval number C08-05).

Financial considerations for spirometry, technicians, and medical care during the study were supported by a grant from the research programs of the INER.

\section{Subjects and recruitment strategies}

Smokers, either with symptoms (WS) (cough, phlegm, wheezing, and shortness of breath) or WOS, were invited to be included for spirometry at no cost during the COPD Day campaigns using mass media advertisements. They were classified as WS or WOS if they had even one symptom or no symptoms at all, respectively. Additionally, all smokers attending our smoking cessation program were also invited for spirometry. The details of both recruitment strategies are described elsewhere. ${ }^{5}$ Those smokers who were aware of having some type of respiratory disease were excluded from this study. As part of the early diagnosis program, tests such as spirometry and a questionnaire regarding respiratory symptoms were completed. All subjects read and signed the "patient information consent form".
Participants were required to be current or former smokers with a cumulative consumption history of at least 10 pack-years. Additionally, subjects fulfilled the following criteria: 1) have a valid pre- and postbronchodilator spirometry; 2) complete a symptom questionnaire; 3 ) no self-report of previous diagnosis of asthma or other pulmonary diseases such as bronchiectasis; and 4) no self-report of a history of exposure to wood smoke or biomass.

\section{Questionnaire}

A brief questionnaire containing 28 items, including age, sex, smoking status, presence of cough, phlegm, wheezing, and shortness of breath, was completed by all participants. Shortness of breath was determined by answering yes or no to the statement "I experience shortness of breath when walking fast on level ground or walking up a slight hill", which corresponds to the modified Medical Research Council (dyspnea scale) grade $1 .{ }^{8}$ In order to appropriately complete the questionnaire and assist smokers, a facilitator was available at all times.

\section{Spirometry}

Subjects were submitted to both pre- and postbronchodilator spirometry following the procedures recommended by the American Thoracic Society and the European Respiratory Society ${ }^{9}$ with a dry rolling-seal volume spirometer (Sensormedics, Yorba Linda, CA, USA). Data were expressed as percent of predicted value using Mexican values of reference equations of Pérez-Padilla et al. ${ }^{10} \mathrm{COPD}$ was defined in accordance with the Global Initiative for Chronic Obstructive Lung Disease (GOLD) guidelines ${ }^{11}$ using a fixed $\mathrm{FEV}_{1}$ / forced vital capacity ratio $(<0.70)$ in long-term smokers who were $>40$ years of age. Severity of airway obstruction was quantified in accordance with GOLD guidelines. ${ }^{12}$

\section{Statistical analysis}

General characteristics were described using mean and standard deviations or median and interquartile range accordingly with variables distribution. Comparisons between groups were done using Student's $t$-test or chi-square test for comparisons between proportions.

In order to determine the predicting factors associated with COPD in asymptomatic subjects, variables such as age, height, weight, sex, pack-years, and tobacco smoking status were estimated using models of uni- and multivariate logistic regression analysis. Cronbach's alpha that was used to estimate the generalizability of the four included items to determine symptoms was 0.71 . 


\section{Results}

Table 1 shows general characteristics according to symptoms in smokers. From the total group of smokers, $21.50 \%$ (637) of subjects had no symptoms, whereas $78.50 \%(2,324)$ had at least one symptom. Subjects WOS were younger, had better lung function, and lower cumulative consumption of cigarettes, both estimated as cigarettes per day and pack-years. From the total group, $11.11 \%(329 / 2,961)$ of smokers had COPD. The prevalence of COPD in subjects WOS was $1.5 \%$ when considering the whole group of smokers $(45 / 2,961)$ and $7 \%$ when considering only the group WOS (45/637). These prevalences were lower when the lower limit of normal was used to estimate the prevalence $(10.01 \%, 1.2 \%$, and $5.65 \%$, respectively).

Table 2 shows differences in COPD according to symptoms. From 329 smokers with COPD, 13.7\% were WOS and $86.3 \%$ WS. Subjects WOS were younger, had better lung function, and median lower cumulative consumption of cigarettes (pack-years). According to the severity of airway limitation, $69 \%$ vs $87 \%$ of subjects were classified as GOLD stages I-II in the WOS and WS groups, respectively $(P<0.000)$, whereas no differences were found between groups for stages III and IV.
Both in the uni- and multivariate regression analysis, $\mathrm{FEV}_{1}(\mathrm{~mL})$ was shown to be a predictive variable for COPD in asymptomatic smokers (Tables 3 and 4).

\section{Discussion}

This group of asymptomatic smokers with COPD represents $\sim 1.5 \%$ from a sample of 2,961 apparently healthy smokers who were screened and 13.7\% (329) of those who had COPD (Table 2). By using the lower limit of normal, the number of asymptomatic smokers with COPD decreased from $1.5 \%$ to $1.2 \%$.

An interesting finding of this work is the fact that $69 \%$ of asymptomatic smokers with COPD were in GOLD stages I and II. This observation may be relevant, considering that recent emerging evidence suggests that subjects in the mild stages of COPD are those with the greatest $\mathrm{FEV}_{1}$ decline. Casanova et $\mathrm{al}^{13}$ found that, in subjects with moderate disease (stage II), the mean loss of $\mathrm{FEV}_{1}$ is higher than in stages III and IV $(-112,-78$ and $-61 \mathrm{~mL} /$ year, respectively). Furthermore, these authors found that $\mathrm{FEV}_{1}$ was significantly higher in decliners with slope change than in subjects without significant slope change $(1,540 \pm 0.60 \mathrm{~mL}$ vs $1,390 \pm 0.54 \mathrm{~mL}$, respectively $P=0.005)$. In another study,

Table I Demographic data of smokers according to the presence of symptoms

\begin{tabular}{|c|c|c|c|}
\hline n (\%) & WOS $637(21.50)$ & WS $2,324(78.50)$ & $P$-value \\
\hline Male, n (\%) & $306(49.90)$ & I,I 60 (49.9I) & 0.401 \\
\hline Age, m (SD) & $49.63(11.33)$ & $51.92(10.48)$ & 0.000 \\
\hline Height cm, m (SD) & $163.04(9.06)$ & $163.06(9.46)$ & 0.972 \\
\hline Weight kg, m (SD) & $71.01(14.28)$ & $71.29(14.83)$ & 0.776 \\
\hline FEV, post-BD mL, m (SD) & $2.97(0.76)$ & $2.80(0.83)$ & 0.000 \\
\hline FEV , post $\%$ predicted, mean (SD) & $98.98(16.55)$ & 94.49 (19.48) & 0.000 \\
\hline $\mathrm{FEV}_{\mathrm{I}} / \mathrm{FVC}$ post \%, m (SD) & $81.03(7.63)$ & $79.10(10.24)$ & 0.000 \\
\hline FVC post mL, m (SD) & $3.66(0.89)$ & $3.53(0.94)$ & 0.000 \\
\hline FVC post $\%$ predicted, m (SD) & $99.90(15.36)$ & $97.25(16.05)$ & 0.000 \\
\hline \multicolumn{4}{|l|}{ Smoking status } \\
\hline Former smoker, n (\%) & $120(18.84)$ & $452(19.45)$ & 0.377 \\
\hline Current smoker, n (\%) & $517(81.16)$ & I,872 (80.55) & 0.377 \\
\hline Years of smoking, m (SD) & $27.53(11.12)$ & $28.79(\mid \mathrm{I} .3 \mathrm{I})$ & 0.019 \\
\hline Cigarettes/day, m (SD) & I $4.53(9.88)$ & $15.85(10.60)$ & 0.009 \\
\hline Pack-years, median (IQR) & $17.00(8-28)$ & $19.50(10-33)$ & 0.012 \\
\hline \multicolumn{4}{|l|}{ Respiratory symptoms } \\
\hline Cough, n (\%) & 0 & $\mathrm{I}, 249(53.74)$ & - \\
\hline Phlegm, n (\%) & 0 & $\mathrm{I}, 417(60.97)$ & - \\
\hline Wheezing, n (\%) & 0 & 137 (5.89) & - \\
\hline Dyspnea, n (\%) & 0 & I,6II (69.32) & - \\
\hline At least one symptom, $\mathrm{n}(\%)$ & 0 & $2,324(100)$ & - \\
\hline COPD prevalence according to fixed GOLD ratio & $45(7.06)$ & $284(12.22)$ & 0.000 \\
\hline COPD prevalence according to LLN & $36(5.65)$ & $264(11.35)$ & 0.000 \\
\hline
\end{tabular}

Note: Data is presented as either $\mathrm{n}(\%)$, mean \pm SD, or median IQR, $\chi^{2}$ test, Student's $t$-test, Mann-Whitney test were used as appropriate.

Abbreviations: BD, bronchodilator; COPD, chronic obstructive pulmonary disease; FEV , forced expiratory volume in I second; FVC, forced vital capacity; GOLD, Global Initiative for Chronic Obstructive Lung Disease; IQR, interquartile range; LLN, lower limit of normal; m, mean; SD, standard deviation; WOS, smokers without symptoms; WS, smokers with symptoms. 
Table 2 Demographic data of COPD patients according to the presence of symptoms

\begin{tabular}{|c|c|c|c|c|}
\hline n (\%) & Total $329(100)$ & WOS 45 (13.7) & WS $284(86.3)$ & $P$-value \\
\hline Male, n (\%) & $195(59.30)$ & $25(55.55)$ & $170(59.85)$ & 0.585 \\
\hline Age, $m(S D)$ & $59.47 \pm 10.19$ & $56.91(9.78)$ & $59.86(10.22)$ & 0.070 \\
\hline Height cm, m (SD) & $164.19 \pm 9.46$ & $166.09(8.97)$ & $163.79(9.54)$ & 0.212 \\
\hline Weight kg, m (SD) & $70.53 \pm 16.08$ & $67.95(14.77)$ & $71.01(16.33)$ & 0.415 \\
\hline FEV, post-BD mL, m (SD) & $1,969 \pm 810$ & $2.20(0.75)$ & $1.93(0.8 I)$ & 0.036 \\
\hline FEV, post-BD \% predicted, m (SD) & $68.92 \pm 26.95$ & $78.52(22.59)$ & $67.42(22.39)$ & 0.002 \\
\hline $\mathrm{FEV}_{\mathrm{I}} / \mathrm{FVC}$ post-BD, m (SD) & $58.84 \pm I 1.00$ & $63.59(11.45)$ & $58.09(11.55)$ & 0.003 \\
\hline FVC post-BD mL, m (SD) & $3,248 \pm I, 050$ & $3.48(1.01)$ & $3.21(1.05)$ & 0.099 \\
\hline FVC post $\%$ predicted, m (SD) & $89.26 \pm 20.97$ & $94.25(22.35)$ & $88.46(20.68)$ & 0.093 \\
\hline Smoking status & Total & & & \\
\hline Former smoker, n (\%) & $64(19.45)$ & $7(15.56)$ & $57(20.07)$ & 0.353 \\
\hline Current smoker, n (\%) & $265(80.55)$ & $38(84.44)$ & $227(79.93)$ & 0.353 \\
\hline Years smoking, m (SD) & $37.83(11.91)$ & $36.04(10.67)$ & 38.10 (12.09) & 0.305 \\
\hline Cigarettes/day, m (SD) & $20.13(13.12)$ & $16.92(12.04)$ & $20.60(13.23)$ & 0.102 \\
\hline Pack-years, median (IQR) & $34.75(|8.7|-5 I .00)$ & $23(13.25-37.00)$ & $36.75(20.00-53.00)$ & 0.013 \\
\hline \multicolumn{5}{|l|}{ Respiratory symptoms } \\
\hline Cough, n (\%) & $165(50.15)$ & - & $165(58.09)$ & - \\
\hline Phlegm, n (\%) & $168(52.66)$ & - & $168(59.15)$ & - \\
\hline Wheezing, n (\%) & I $37(42.94)$ & - & I $37(48.23)$ & - \\
\hline Dyspnea, n (\%) & $224(70.21)$ & - & 224 (78.87) & - \\
\hline \multicolumn{5}{|l|}{ COPD severity (GOLD) } \\
\hline I-II, n (\%) & $279(84.80)$ & $31(68.88)$ & $248(87.32)$ & 0.000 \\
\hline III-IV, n (\%) & $50(\mid 5.20)$ & $14(31.12)$ & $36(12.68)$ & 0.296 \\
\hline
\end{tabular}

Note: Data is presented as either $\mathrm{n}(\%)$, mean \pm SD, or median IQR, $\chi^{2}$ test, Student's $t$-test, Mann-Whitney test were used as appropriate.

Abbreviations: BD, bronchodilator; COPD, chronic obstructive pulmonary disease; FEV , forced expiratory volume in I second; FVC, forced vital capacity; GOLD, Global Initiative for Obstructive Lung Disease; IQR, interquartile range; m, mean; SD, standard deviation; WOS, smokers without symptoms; WS, smokers with symptoms.

Ramírez-Venegas et $\mathrm{l}^{14}$ found a significantly higher number of rapid decliners in subjects with mild and moderate stages (GOLD II) in comparison to those with the lower FEV (GOLD stages III and IV). Additionally, in an analysis of the Framingham offspring cohort, Kohansal et $\mathrm{al}^{15}$ found that, in the asymptomatic subject with diagnosis of COPD (as in this study), the rate of $\mathrm{FEV}_{1}$ decline was increased in comparison to healthy continuous smokers and healthy never-smokers. Another important point to be considered is that COPD is associated with a substantial burden on the health care systems, mainly attributable to the occurrence of exacerbations. ${ }^{16}$

Table 3 Factors associated with COPD in asymptomatic subjects (univariate analysis)

\begin{tabular}{|c|c|c|c|}
\hline Variable & OR & $95 \% \mathrm{Cl}$ & $P$-value \\
\hline Sex* & 0.838 & $0.444-1.580$ & 0.585 \\
\hline Current smoker & $\mathrm{I} .534$ & $0.061-3.812$ & 0.356 \\
\hline Cigarettes/day & 0.975 & $0.945-1.005$ & 0.103 \\
\hline $\mathrm{FEV}_{1}, \mathrm{~mL}$ & 1.485 & $1.021-2.159$ & 0.038 \\
\hline Age, years & 1.002 & $0.976-1.029$ & 0.833 \\
\hline Pack-years & 0.988 & $0.974-1.002$ & 0.101 \\
\hline Height, cm & 1.025 & $0.985-1.067$ & 0.213 \\
\hline Weight, kg & 0.987 & $0.957-0.017$ & 0.413 \\
\hline
\end{tabular}

Note: *Reference category: female.

Abbreviations: $\mathrm{Cl}$, confidence interval; COPD, chronic obstructive pulmonary disease; $\mathrm{FEV}_{1}$, forced expiratory volume in I second; OR, odds ratio.
The majority of asymptomatic subjects described in this work, although classified as GOLD stages I and II according to the Evaluation of COPD Longitudinally to Identify Predictive Surrogate Endpoints study, ${ }^{17}$ are susceptible as well to exacerbations, irrespective of disease severity. An additional and appealing finding consistently reported by Ohar et al ${ }^{18}$ relating to potential costs of the disease is that $10 \%$ of asymptomatic subjects with COPD from this study had important airflow limitations (GOLD stages III and IV). In this group of patients, the frequency ${ }^{17}$ recurrence rates, and health care utilization are significantly higher.

Asymptomatic smokers with COPD have been previously described in small groups of subjects with emphysema using magnetic resonance imaging of the lungs. ${ }^{19}$ In another study, 29/75 smokers had emphysema and significantly higher mean

Table 4 Factors associated with COPD in asymptomatic subjects (multivariate analysis)

\begin{tabular}{llll}
\hline Variables & OR & $\mathbf{9 5 \% ~ C l}$ & $P$-value \\
\hline $\mathrm{FEV}_{1}, \mathrm{~mL}$ & 2.05 & $1.22-3.40$ & 0.006 \\
Sex I = male & 0.64 & $0.29-1.42$ & 0.259 \\
Smoking index, pack-years & 0.99 & $0.97-1.00$ & 0.099 \\
\hline
\end{tabular}

Abbreviations: $\mathrm{Cl}$, confidence interval; COPD, chronic obstructive pulmonary disease; $\mathrm{FEV}_{1}$, forced expiratory volume in I second; OR, odds ratio. 
values of functional residual capacity, residual volume, and total lung capacity than smokers without emphysema. ${ }^{20}$ When these subjects (GOLD stage I) become symptomatic, end-expiratory lung volume during exercise is greater and breathing pattern more shallow and rapid. ${ }^{21}$ Results from O'Donnell et $\mathrm{al}^{22}$ show that if these smokers (GOLD stage I) are treated with bronchodilators, modest but consistent improvements are observed in airway function, lung volume, and exercise dyspnea. In another study, it was found that out of 1,269 smokers with COPD (44\% from their original sample of smokers), $14.3 \%$ had no symptoms. ${ }^{18}$ Of these smokers, only $2.5 \%$ had received a diagnosis of COPD, suggesting that the lack of symptoms is a risk factor for undiagnosed COPD. Consistent with this finding, data from the Proyecto LatinoAmericano de Investigación en Obstrucción Pulmonar study ${ }^{23}$ showed that the absence of respiratory symptoms increases the likelihood of undiagnosed COPD. Accordingly, our results showed that the higher level of FEV predicted COPD in asymptomatic smokers, suggesting that being asymptomatic as well as having better lung function prevents early suspicion and diagnosis of COPD. ${ }^{24}$

Do symptoms predict COPD in smokers? Symptoms are frequent in smokers. In the current study, $78.5 \%$ of 2,961 subjects had at least one symptom and, of these, 284 (8.18\%) had COPD. However, it appears that symptoms are poor predictors of the presence of COPD in smokers at risk. ${ }^{18}$ Therefore, given the low added sensitivity to smoking history and age, an alternative approach to early diagnosis is needed.

Establishing an early diagnosis of COPD is important both for advanced as well as for mild cases of the disease. There are several reasons for this: first, exacerbations are frequent in all stages of the disease ${ }^{17}$ and are associated with an accelerated rate of decline in $\mathrm{FEV}_{1}{ }^{25}$ and worsening of quality of life. ${ }^{26}$ Second, pharmacological intervention in moderate disease reduces the rate of decline of $\mathrm{FEV}_{1}{ }^{27,28}$ and mortality, even after adjustments according to GOLD stages. ${ }^{29}$ Likewise, pharmacological treatment may reduce exacerbations by the same mechanisms through which bronchodilators prevent exacerbations in severe stages of the disease. ${ }^{30}$ Nevertheless, the US Preventive Services Task Force review from $2008^{31}$ concluded that the efficiency of treatment has been established only in symptomatic patients. Therefore, the benefits in this population are speculative. In this sense, it is noteworthy to observe that the post hoc data from the Understanding Potential Long-term Impacts on Function with Tiotropium study showing that treatment provides clinical efficacy by improving the health status and decreasing time to first and severe exacerbations ${ }^{27}$ have been described in patients with $\mathrm{FEV}_{1} \geq 60 \%$ predicted (GOLD stage II). ${ }^{32}$

Most of the identified asymptomatic subjects from this study with COPD had $\mathrm{FEV}_{1}$ within the "normal" range. Whether these subjects will progress to develop symptomatic and clinically significant airflow disease largely remains unknown. ${ }^{15}$ Nevertheless, according to Price et al, ${ }^{33}$ the perception of symptoms may be different or dismissed in some individuals despite being limited in terms of their daily activities and health-related quality of life. ${ }^{34}$ In this sense, the frequent and consistent finding of undiagnosed $\mathrm{COPD}^{35}$ is the responsibility of both patients and physicians. On the one hand, an important number of smokers do not seek medical help prior to symptom onset ${ }^{36}$ and, on the other hand, a minority of respiratory physicians indicates the use of spirometry to smokers. ${ }^{37}$

\section{Conclusion}

In summary, growing clinical positions state the need for "early and earlier" 33 diagnosis of COPD to prevent late consequences of the disease. Most of these are based on case-finding strategies where symptoms and history of heavy tobacco smoking are the main indicators for spirometry. Our results suggest that a number of asymptomatic smokers may be excluded from the benefit of an "early" intervention, not just pharmacological but also from smoking cessation counseling. Therefore, screening all heavy smokers aged $>40$ years with a history of $\geq 20$ pack-years, WS or WOS, with spirometry, may help to resolve the universal issue of underdiagnosed COPD. However, our results should be interpreted with caution when considering the recent US Preventive Services Task Force review ${ }^{31}$ stating some inconveniences of the screening programs on COPD such as the effects of overdiagnosis, the possibility of unnecessary treatment, and potential side effects of the spirometric maneuver. ${ }^{31}$ An additional limitation of this work is that the questionnaire did not search for passive smoking and the possible effects on prevalence of COPD in asymptomatic smokers.

\section{Acknowledgments}

The authors acknowledge the participation of the chronic obstructive pulmonary disease clinic staff that contributed to clinical care of the study participants. This work is supported by a research grant from the Instituto Nacional de Enfermedades Respiratorias Ismael Cosío Villegas (INER) (protocol C08-05). 


\section{Disclosure}

The authors report no conflicts of interest in this work.

\section{References}

1. Lopez AD, Shibuya K, Rao C, et al. Chronic obstructive pulmonary disease: current burden and future projections. Eur Respir J. 2006;27(2): $397-412$.

2. Zielinski J, Bednarek M, Know the Age of Your Lung Study Group. Early detection of COPD in a high-risk population using spirometric screening Chest. 2001;119(3):731-736.

3. Duvall K, Frank GW. Identifying chronic obstructive pulmonary disease in primary care of urban underserved patients: tools, applications, and challenges. J Natl Med Assoc. 2010;102(7):570-578.

4. Balcells E, Antó JM, Gea J, et al; PAC-COPD Study Group. Characteristics of patients admitted for the first time for COPD exacerbation. Respir Med. 2009;103(9):1293-1302.

5. Zielinski J, Bednarek M, Górecka D, et al. Increasing COPD awareness. Eur Respir J. 2006;27(4):833-852.

6. Sansores RH, Ramírez-Venegas A, Hernández-Zenteno R, Mayar-Maya ME, Pérez-Bautista OG, Velázquez Uncal M. Prevalence and diagnosis of chronic obstructive pulmonary disease among smokers at risk. A comparative study of case-finding vs. screening strategies. Respir Med. 2013;107(4):580-586.

7. Montes de Oca M, López-Varela MV, Acuña A, et al. ALAT-2014 Chronic Obstructive Pulmonary Disease (COPD) Clinical Practice Guidelines: questions and answers. Formación de Preguntas Clínicas en Formato PICO. Arch Bronconeumol. 2015;51(8):403-416.

8. Bestall JC, Paul EA, Garrod R, Garnham R, Jones PW, Wedzicha JA. Usefulness of the Medical Research Council (MRC) dyspnea scale as a measure of disability in patients with chronic obstructive pulmonary disease. Thorax. 1999;54(7):581-586.

9. Miller MR, Hankinson J, Brusasco V, et al; ATS/ERS Task Force. Standardization of spirometry. Eur Respir J. 2005;26(2):319-338.

10. Pérez-Padilla R, Valdivia G, Muiño A, et al. Spirometric reference values in 5 large Latin American cities for subjects aged 40 years or over. Arch Bronconeumol. 2006;42(7):317-325.

11. Rabe KF, Hurd S, Anzueto A, et al; Global Initiative for Chronic Obstructive Lung Disease. Global strategy for the diagnosis, management, and prevention of chronic obstructive pulmonary disease: GOLD executive summary. Am J Respir Crit Care Med. 2007;176(6):532-555.

12. Celli BR, MacNee W, ATS/ERS Task Force. Standards for the diagnosis and treatment of patients with COPD: a summary of the ATS/ERS position paper. Eur Respir J. 2004;23(6):932-946.

13. Casanova C, de Torres JP, Aguirre-Jaíme A, et al. The progression of chronic obstructive pulmonary disease is heterogeneous: the experience of the BODE cohort. Am J Respir Crit Care Med. 2011;184(9): 1015-1021.

14. Ramírez-Venegas A, Sansores RH, Quintana-Carrillo RH, et al. Forced expiratory volume in one second decline in patients with chronic obstructive pulmonary disease associated with biomass exposure. Am J Respir Crit Care Med. 2014;190(9):996-1002.

15. Kohansal R, Martínez-Camblor P, Agustí A, Buist AS, Mannino DM, Soriano JB. The natural history of chronic airflow obstruction revisited: an analysis of the Framingham offspring cohort. Am J Respir Crit Care Med. 2009;180(1):3-10.

16. Blasi F, Cesana G, Conti S, et al. The clinical and economic impact of exacerbations of chronic obstructive pulmonary disease: a cohort of hospitalized patients. PLoS One. 2014;9(6):e101228.

17. Hurst JR, Vestbo J, Anzueto A, et al; Evaluation of COPD Longitudinally to Identify Predictive Surrogate Endpoints (ECLIPSE) Investigators. Susceptibility to exacerbation in chronic obstructive pulmonary disease. N Engl J Med. 2010;363(12):1128-1138.

18. Ohar JA, Sadeghnejad A, Meyers DA, Donohue JF, Bleecker ER. Do symptoms predict COPD in smokers? Chest. 2010;137(6): 1345-1353.
19. Fain SB, Panth SR, Evans MD, et al. Early emphysematous changes in asymptomatic smokers: detection with $3 \mathrm{He}$ MR imaging. Radiology. 2006;239(3):875-883.

20. Yasunaga K, Chérot-Kornobis N, Edmé JL, et al. Emphysema in asymptomatic smokers: quantitative CT evaluation in correlation with pulmonary function tests. Diagn Interv Imaging. 2013;94(6):609-617.

21. Ofir D, Laveneziana P, Webb KA, Lam YM, O'Donnell DE. Mechanisms of dyspnea during cycle exercise in symptomatic patients with GOLD stage I chronic obstructive pulmonary disease. Am J Respir Crit Care Med. 2008;177(6):622-629.

22. O'Donnell DE, Laveneziana P, Ora J, Webb KA, Lam YM, Ofir D. Evaluation of acute bronchodilator reversibility in patients with symptoms of GOLD stage I COPD. Thorax. 2009;64(3):216-223.

23. Tálamo C, Montes de Oca M, Halbert R, et al; PLATINO team. Diagnostic labeling of COPD in five Latin American cities. Chest. 2007;131(1): 60-67.

24. Elbehairy AF, Raghavan N, Cheng S, et al. Physiological characterization of the chronic bronchitis phenotype in GOLD grade 1B COPD. Chest. 2015;147(5):1235-1245.

25. Donaldson GC, Seemungal TA, Bhowmik A, Wedzicha JA. Relationship between exacerbation frequency and lung function decline in chronic obstructive pulmonary disease. Thorax. 2002;57(10):847-852.

26. Seemungal TA, Donaldson GC, Paul EA, Bestall JC, Jeffries DJ, Wedzicha JA. Effect of exacerbation on quality of life in patients with chronic obstructive pulmonary disease. Am J Respir Crit Care Med. 1998; 157(5 pt 1):1418-1422.

27. Decramer M, Celli B, Kesten S, et al. Effect of tiotropium on outcomes in patients with moderate chronic obstructive pulmonary disease (UPLIFT): a prespecified subgroup analysis of a randomised controlled trial. Lancet. 2009;374(9696):1171-1178.

28. Celli BR, Thomas NE, Anderson JA, et al. Effect of pharmacotherapy on rate of decline of lung function in chronic obstructive pulmonary disease: results from the TORCH study. Am J Respir Crit Care Med. 2008; 178(4):332-338.

29. Celli B, Decramer M, Kesten S, Liu D, Mehra S, Tashkin DP; UPLIFT Study Investigators. Mortality in the 4-year trial of tiotropium (UPLIFT) in patients with chronic obstructive pulmonary disease. Am J Respir Crit Care Med. 2009;180(10):948-955.

30. Wedzicha JA, Calverley PM, Seemungal TA, Hagan G, Ansari Z, Stockley RA; INSPIRE Investigators. The prevention of chronic obstructive pulmonary disease exacerbations by salmeterol/fluticasone propionate or tiotropium bromide. Am J Respir Crit Care Med. 2008; 177(1):19-26.

31. US Preventive Services Task Force. Screening for chronic obstructive pulmonary disease using spirometry: U.S. Preventive Services Task Force recommendation statement. Ann Intern Med. 2008;148: 529-534.

32. Tashkin DP, Li N, Kleerup EC, et al. Acute bronchodilator responses decline progressively over 4 years in patients with moderate to very severe COPD. Respir Res. 2014;15:102-105.

33. Price D, Freeman D, Cleland J, Kaplan A, Cerasoli F. Earlier diagnosis and earlier treatment of COPD in primary care. Prim Care Respir J. 2011;20(1):15-22.

34. Miravitlles M, Soriano JB, García-Río F, et al. Prevalence of COPD in Spain: impact of undiagnosed COPD on quality of life and daily life activities. Thorax. 2009;64(10):863-868.

35. Decramer M, Miravitlles M, Price D, et al. New horizons in early stage COPD-improving knowledge, detection and treatment. Respir Med.2011; 105(11):1576-1587.

36. Miravitlles M, de la Roza C, Morera J, et al. Chronic respiratory symptoms, spirometry and knowledge of COPD among general population. Respir Med. 2006;100(11):1973-1980.

37. Miravitlles M, de la Roza C, Naberan K, Lamban M, Gobartt E, Martin A. Use of spirometry and patterns of prescribing in COPD in primary care. Respir Med. 2007;101(8):1753-1760. 
International Journal of COPD

\section{Publish your work in this journal}

The International Journal of COPD is an international, peer-reviewed journal of therapeutics and pharmacology focusing on concise rapid reporting of clinical studies and reviews in COPD. Special focus is given to the pathophysiological processes underlying the disease, intervention programs, patient focused education, and self management protocols

\section{Dovepress}

This journal is indexed on PubMed Central, MedLine and CAS. The manuscript management system is completely online and includes a very quick and fair peer-review system, which is all easy to use. Visit $\mathrm{http}: / / \mathrm{www}$.dovepress.com/testimonials.php to read real quotes from published authors.

Submit your manuscript here: http://www.dovepress.com/international-journal-of-chronic-obstructive-pulmonary-disease-journal 